\title{
Granular Cell Tumor of Breast: Rare Tumor Masquerading as Malignancy
}

\author{
Suzita Hirachan ${ }^{1}$, Yogendra P Singh ${ }^{1}$, Anamika Jha², Usha Manandhar ${ }^{3}$ \\ ${ }^{1}$ Breast Unit, Department of Surgery, ${ }^{2}$ Department of Radiology, ${ }^{3}$ Department of Pathology, Maharajgunj Medical \\ Campus, Tribhuvan University Teaching Hospital, Institute of Medicine, Kathmandu, Nepal
}

\section{Corresponding author:}

Suzita Hirachan, MBBS, MS

Breast Unit, Department of Surgery, Maharajgunj Medical Campus, Tribhuvan University Teaching Hospital, Institute of Medicine, Kathmandu, Nepal

Email:drsuzita@gmail.com

Submitted : Feb 20, 2020

Accepted : Mar 25, 2020

\begin{abstract}
Granular cell tumor (GCT) is a rare soft tissue tumor that arises from the Schwann cells of peripheral nerves. It was first postulated by Abrikossoff in 1926 as Myoblastoma. About 5-15\% of these tumors occur in the breast and less than $1 \%$ has the potential to be malignant. Here we present a case of 41 years old premenopausal woman with Benign GCT of the right breast, having clinically malignant features. The clinical and radiological features of GCT are similar to malignant lump. However, histology showing presence of sheets of polygonal cells with abundant granular eosinophilic cytoplasm with round nuclei and granules with Periodic acid-Schiff (PAS) positive, diastase resistant and S-100 antigen positive are confirmatory. Treatment of Granular cell tumor is wide local excision. There is apparently no role of chemotherapy and radiotherapy. The presence of GCT in the breast is quite rare and clinically as well as radiologically it may mimic malignancy, however with histopathology and appropriate immunohistochemistry, proper diagnosis can be made.
\end{abstract}

Keywords: Breast cancer, excision, granular cell tumor

\section{INTRODUCTION}

G ranular cell tumors (GCTs), rare soft tissue tumors were first fully described by Abrikossoff in 1926. ${ }^{1} \mathrm{GCT}$, initially known as granular cell myoblastoma, are rare neoplasm of Schwann cell origin, composed of cells with granular eosinophilic cytoplasm. They show positive S-100. They commonly affect premenopausal women. ${ }^{2}$ They can occur in any part of the body like head, neck, chest wall, dermis, oral mucosa including tongue, breast and gastrointestinal tracts. ${ }^{3,4}$

Granular cell tumors of the breast account for $5-15 \%$ of all GCTs and approximately 1 in 1000 cases of breast cancer. They mostly occur in the upper, inner quadrant of breast in contrast to breast carcinoma. ${ }^{5} \quad$ Sometimes, granular cell tumor of the breast can coexist with an ipsilateral infiltrating ductal carcinoma and even in the mastectomy scars lesions. ${ }^{6}$

\section{CASE PRESENTATION}

A 41-years-old multiparous, premenopausal lady presented in Breast Clinic of Surgery Department with a history of right breast lump for four months. The lump was gradually increasing in size, painless and not associated with any nipple discharge. Past medical history was not significant. 


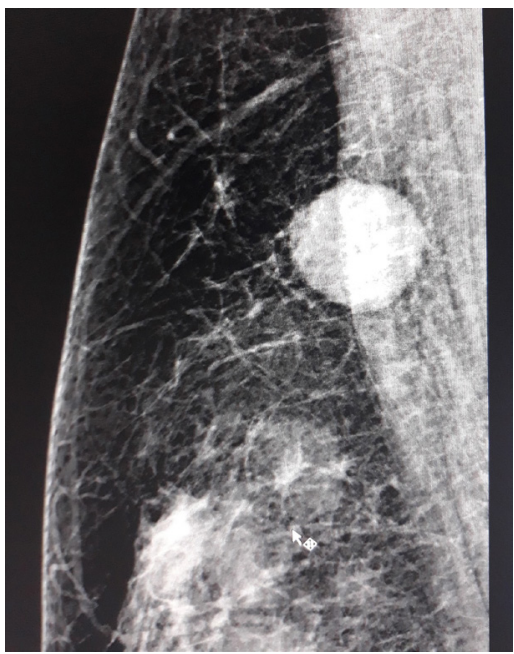

Fig 1. Mammogram right MLO view showing circumscribed high density lesion in superior aspect in sub-axillary region

On examination, the patient's Eastern Cooperative Oncology Group (ECOG) Performance Status was ' 0 '. General and systemic examination of the patient was normal. On local examination of bilateral breasts and axilla, there was a lump of $3 X 2 \mathrm{~cm}$ over upper and outer quadrant of the right breast. On palpation, the swelling was very hard, non-tender, mobile, without underlying chest wall fixity and normal overlying skin. Bilateral axilla and left breast were normal.

Ultrasonography showed 19X14 mm sized, hypoechoic lesion with irregular margins over the right mid-clavicular region in superior aspect of the right breast. The lesion had minimal internal vascularity suggesting malignancy. Mammography revealed Breast Imaging, Reporting \& Data System (BIRADS-3) in right breast (Figure 1) and normal left breast.

Ultrasound guided true cut biopsy showed sheets of tumor cells with abundant granular cytoplasm, rounded nuclei with inconspicuous nucleoli suggestive of granular cell tumor.

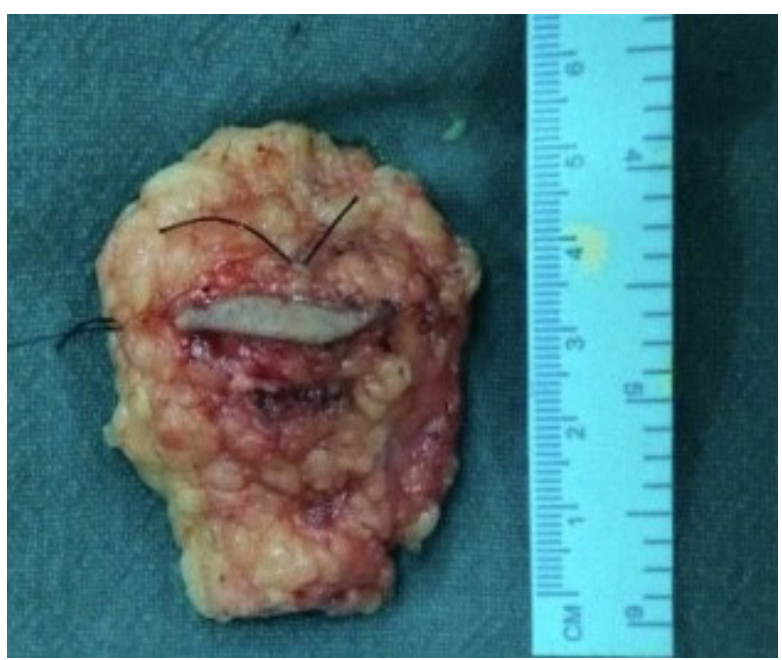

Fig 2. Gross finding of excised breast mass. (Short thread-superior and long thread-lateral)

We performed wide local excision of the right breast granular cell tumor with adequate margin and the defect was closed primarily. The excised mass was of size $5 \times 4.5 \mathrm{~cm}$ size (Figure 2).

Postoperative course in the hospital was uneventful and she was discharged on 1stpostoperative day.

Histopathological gross report consisted of single piece of globular fatty tissue of $5 \times 4.5 \times 2 \mathrm{~cm}$ with skin ellipse. Cut section showed grey white homogenous areas without hemorrhage or necrosis. Cystic changes were seen. Microscopically, there were sheets of polygonal cells with abundant granular eosinophilic cytoplasm with round nuclei (Figure 3a). Atypical/necrosis/mitosis were not seen. Granules were Periodic acid-Schiff (PAS) stain positive and diastase resistant with S-100 antigen positive (Figure 3b, 3c). Resection margins were free of tumor. The diagnosis of benign granular cell tumor was made with all resected margins free.

Patient was on regular follow-up without any surgical site infection and suture removed on $7^{\text {th }}$ postoperative day. Patient is on regular follow-up and clinically free of disease for eight months now.
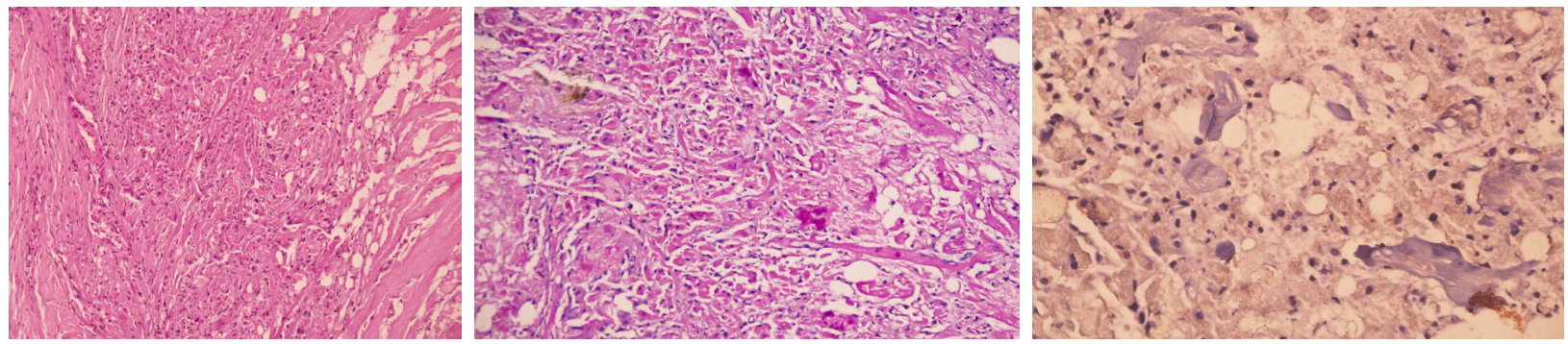

Fig 3a. Sheets of polygonal tumor cells having abundant granular eosinophilic cytoplasm with small round nuclei (Hematoxylin-Eosin x 200). 3b. Cytoplasmic granules are periodic acid schiff positive and diastase resistant (PAS-D stain, x200). 3c. Positivity of cytoplasmic granules for S-100 protein ( S100, x400) 


\section{DISCUSSION}

Granular cell tumors are usually asymptomatic and present as slow-growing, solitary nodules in subcutaneous or sub mucosal regions. They develop in the breast in about $5-15 \%$ of cases. They are more common in African American women of premenopausal age.5,7 Approximately 0.5\%-2.0\% of GCTs are found to be malignant. Malignant GCTs are more aggressive and have poor prognosis, whereas benign lesions have excellent outcomes after surgical resection. ${ }^{8}$

Fanburg Smith et al $^{9}$ proposed the following six criteria from a histopathologic perspective to determine the malignant granular tumor: the presence of necrosis, spindle cells emergence, a vacuolar nucleus with an enlarged nuclear body, increase in nuclear division (2 mitoses/10 HPF), increase in the nucleoplasmic ratio and polymorphism. The tumor is considered to be benign if none of these diagnostic criteria are met. If one or two criteria are met, the tumor is considered to be atypical, and if three or more criteria are met, the tumor is considered to be malignant.

At times, GCTs of breast mimic scirrhous breast malignancies and are hard to distinguish from them via clinical, radiological, or other diagnostic techniques. Misdiagnosis of malignancy can lead to inappropriate radical treatment resulting in unnecessary physical and mental stress. ${ }^{10}$

In this case, GCT was present in upper outer quadrant as in carcinoma though most common location is upper, inner quadrant. ${ }^{5}$ Apart from the location, rest of the physical findings and pathological characteristics of the tumor in our case was in tandem with the published literature disguising as a malignant tumor with hard consistency. Although mammography reporting as BIRADS-3 and ultrasound as hypo echoic lesion with irregular margins were obscure; core biopsy confirmed the diagnosis.

The treatment of both benign and malignant granular cell tumor is surgical resection as the tumor is uncapsulated and is proliferation invasive. There is no adequate efficacy of chemotherapy and radiotherapy. ${ }^{11}$ Benign granular cell tumor has excellent prognosis however recurrence rate after excision with wide margin is $2-8 \% .^{12}$

\section{CONCLUSION}

Although GCTs are usually benign and slow growing, it is difficult to distinguish them from malignant lesions clinically as well as radiologically. Therefore, it is very important that the surgeons should be aware of the significance of histopathological and immunohistochemical characteristics in these lesions.

\section{CONFLICT OF INTEREST}

None declared.

\section{REFERENCES}

1. Filipovski V, Banev S, Janevska V et al. Granular cell tumor of the breast: a case report and review of literature. Cases J. 2009 Aug10;2:8551.

2. Alnashwan YA, Ali KAH, Amr SS. Metastasizing Malignant Granular Cell Tumor (Abrikossoff Tumor) of the Anterior Abdominal Wall, with Prolonged Survival. Case Rep Pathol. 2019 Apr 7;2019:9576487.

3. Adeniran A, Al-AhmadieH, Mahoney $\mathrm{MC}$ et al. Granular cell tumor of the breast: a series of 17 cases and review of the literature. Breast J. 2004 Nov-Dec;10(6):528-31.

4. Singhi AD, Montgomery EA. Colorectal granular cell tumor: a clinicopathologic study of 26 cases. Am J SurgPathol. 2010 Aug;34(8):1186-92.

5. Fujiwara K, Maeda I, Mimura H. Granular cell tumor of the breast mimicking malignancy: a case report with a literature review. ActaRadiol Open. 2018 Dec 10;7(12):2058460118816537.

6. Tran TA, Kallakury BV, Carter et al. Coexistence of granular cell tumor and ipsilateral infiltrating ductal carcinoma of the breast. South Med J. 1997 Nov;90(11):1149-51.

7. Qureshi NA, Tahir M, Carmichael AR. Granular cell tumor of the soft tissues: a case report and literature review. IntSeminSurgOncol. 2006 Aug $24 ; 3: 21$.

8. Singh VA, Gunasagaran J, Pailoor J. Granular cell tumor: malignant or benign? Singapore Med J. 2015 Sep;56(9):513-7.

9. Fanburg-Smith JC, Meis-Kindblom JM, Fante $\mathrm{R}$ et al. Malignant granular cell tumor of soft tissue: diagnostic criteria and clinicopathologic correlation. Am J Surg Pathol. 1998 Jul;22(7):77994.

10. Kragel PJ, Fiorella RM, Kremer H. Tumoral fibrosis and lack of circumscription in granular cell tumor of the breast. South Med J. 1995 Nov;88(11):11468.

11. Aoyama K, Kamio T, Hirano A et al. Granular cell tumors: a report of six cases. World J SurgOncol. 2012 Sep 29;10:204.

12. Brown AC1, Audisio RA, Regitnig P. Granular cell tumor of the breast.SurgOncol. 2011;20:97-105. 